\title{
La marca figurado en los diccionarios de uso ${ }^{1}$
}

\author{
Rosario González Pérez \\ Universidad Autónoma de Madrid
}

\section{LA MARCA FIGURADO COMO MARCA DEL PRIMER ENUNCIADO}

El profesor Manuel Seco (1987), en su ya clásico libro Estudios de lexicografía española, se refiere a la marca figurado, que encabeza no pocas acepciones lexicográficas en el diccionario de uso académico, incluyéndola dentro de la información que el repertorio ofrece de una unidad léxica; pertenecería, pues, a lo que se denomina el "primer enunciado del artículo lexicográfico", en el que se encuentra una información dispersa sobre el lexema definido (etimología, categoría gramatical, época de vigencia, límites geográficos, etc...) que se encuentra rígidamente ordenada en cuanto al lugar ocupado en el artículo, a la forma de predicación y a la presentación gráfica. Estas informaciones del primer enunciado, sin ser propiamente semánticas, matizan el significado de los términos ya que nos ofrecen valiosos datos sobre su vigencia, extensión y, en definitiva, sobre su uso. La marca figurado, siguiendo al profesor Seco, pertenecería al grupo de marcas encargado de dar cuenta de las transiciones semánticas del vocablo en cuestión, al igual que otro tipo de indicaciones como por extensión, por antonomasia o irónico; y, lo que es más interesante, en este tipo de marcas -cito textualmente- "esta información, lógicamente, sólo en acepciones se-

1 Una vez redactado este estudio y preparado para su publicación, he tenido noticia del trabajo inédito (que ya se habrá publicado en esta misma revista cuando vea la luz el mío) "La marca de transición semántica: sentido figurado" de J. C. Hoyos [Revista de Lexicografía, VI, 1999-2000, pp. 73-105]. 
cundarias" 2 . Dos conclusiones se extraen de lo que venimos diciendo, por un lado, la marca figurado debería informar sobre la evolución semántica del término, por otro, señala una acepción secundaria genéticamente, es decir, derivada de otra, en principio anterior cronológicamente a la figurada, con la que guardará relación precisamente genética, sea patente o no el parentesco semántico entre ambas. No es asunto baladí para un lexicógrafo el carácter de evolución que confiere la marca que estudiamos a la acepción que acompaña, pues ya hemos dicho que la información del primer enunciado está rígidamente ordenada dentro del artículo lexicográfico. En las "Advertencias preliminares para el uso de este diccionario" que ofrece el DRAE923 , el párrafo III se dedica a explicar el orden de las acepciones en cada artículo diciendo: "Dentro de cada artículo van colocadas por este orden las diversas acepciones de los vocablos, primero las de uso corriente; después las anticuadas, las familiares, las figuradas, las provinciales e hispanoamericanas, y, por último, las técnicas y de germanía" (1992: xxi). El hecho de situar encabezando el artículo la acepción usual obliga al redactor a difíciles decisiones, sobre todo en lo que se refiere a acepciones con marca de evolución semántica, pues ha de separar las que son producto de un cambio y situarlas en el lugar que les corresponda, bajo la acepción de la que provengan. Esta tarea no es en absoluto sencilla: tengamos en cuenta que, anunque se haya insistido mucho en ello, seguimos careciendo de un diccionario del español como lengua histórica, con lo que las marcas de transición semántica constituyen siempre un problema ante el cual el redactor se ve obligado a decidir cuál es la acepción que da lugar a dicha transición y qué acepciones deben llevar la marca figurado. Y en un diccionario usual, que ha de revisarse y publicarse periódicamente, no pueden hacerse monografías léxicas para cada entrada, pues la tarea de revisión no terminaría nunca.

2 Cito por Seco (1987), pp. 15-34; especialmente 15-16.

3 Así nos referiremos al diccionario de uso académico en su última edición (21 $\left.{ }^{\mathrm{a}}.\right)$, repertorio del que hemos partido en este trabajo. 


\section{ACEPCIONES QUE INCORPORAN LA MARCA FIGURADO}

Efectivamente, no todas las acepciones esperables llevan dicha marca. El carácter secundario evolutivamente de las acepciones figuradas lleva a que predomine un criterio morfosemántico para su adición a determinadas acepciones. Por ejemplo, cuando un lexema, sea cual sea su categoría gramatical ha generado una acepción figurada, ésta se sitúa en el orden que le corresponde tras la acepción de la que deriva, como en el caso de rabioso, sa que a partir de la primera acepción adjetiva 'que padece rabia' genera las acepciones figuradas segunda 'colérico, enojado, airado' y cuarta 'vehemente, excesivo, violento'. Pero cuando un lexema es figurado porque ha habido una evolución semántica que lo ha apartado del significado prototípico y pertenece, además, a otra categoría gramatical distinta de la del lexema con el que guarda relación de parentesco semántico, nos encontramos con un criterio morfosemántico en que prima la categoría gramatical, ya que sólo aparece la marca figurado en la entrada de la palabra-madre. Esto sucede en rapo$s a$, cuyo primer significado remite a zorral 'animal', que genera una tercera acepción figurada y familiar 'persona astuta'. Sobre esta tercera acepción se crea el verbo intransitivo raposear, que el DRAE92 define como 'emplear ardides y trampas', pero ya sin la marca figurado. Recordemos que el profesor Seco confería a esta marca un carácter de indicador de acepción secundaria, por tanto, si no hay acepción que inicie el proceso de transición semántica no cabría la explicitación de la marca figurado. Esta es la forma de proceder del DRAE92 en estos casos. Veamos ahora la entrada rabiosamente; este adverbio de modo se define en su primera acepción como 'con ira, enojo, cólera o rabia', sin la marca de uso figurado, pues en el adjetivo rabioso, del que deriva, ya está marcado así este significado en las acepciones segunda y cuarta. El criterio es el mismo que en el caso de raposear, pero en rabiosamente hay una segunda acepción 'violenta, intensa o vehementemente. Es RABIOSAMENTE guapa', que sí lleva la marca figurado, pues siguiendo el criterio ordenador del DRAE92, hay acepción de la que derivarla semánticamente; este procedimiento, que deja intacta y coherente la microestructura del repertorio, afecta profundamente a la macroestructura del mismo porque ofrece un tratamiento distinto a entradas afecta- 
das por los mismos procesos semánticos, como sucede en los casos de rabioso y rabiosamente.

Sin embargo, encontramos también ejemplos dentro de la letra $\mathrm{R}$-de donde hemos extraído los materiales para elaborar este estudio-, en que un lexema derivado formalmente de otro, pero sólo en uno de sus significados, precisamente el figurado, encabeza su primera acepción como entrada independiente, precisamente por la marca figurado: el adjetivo rabanero, ral comienza con una primera acepción 'adj. fig. y fam. Dícese de los ademanes y modo de hablar ordinarios y desvergonzados'. Hay otros casos en que un lexema se marca ya en su primera acepción como figurado sin que la palabra así marcada derive de otra a partir de una acepción figurada; lo que sucede entonces es que existen dos lexemas de orígenes etimológicos diferentes, homonimia diacrónica que el repertorio académico indica numerando en entradas diferentes los términos homónimos. Así nos encontramos con rajar2, de un hipotético * radulare latino, según la Academia, cuya primera acepción es 'intr. fig. y fam. Decir o contar muchas mentiras, especialmente jactándose de valiente y hazañoso', y la segunda 'fig. y fam. Hablar mucho'; en la letra $\mathrm{P}$ tenemos un caso idéntico pollo2 -sin etimología- ' $\mathrm{m}$. fig. $\mathrm{y}$ fam. Escupitajo, esputo'. Con esto vemos que hay un distinto tratamiento semántico para las entradas que generan usos figurados y derivan de una acepción ya figurada y las que se consideran entradas independientes por el distinto origen de su lema, o bien (sospechamos que ese es el caso de rabanero, ral y de pollo2) tan separados en significado de la palabra de la que parten que se opta por reflejar la hominimia sincrónica lexicográficamente ${ }^{4}$.

Esta forma de proceder lleva a una información no pertinente en un diccionario sincrónico, pues nos orienta, en las entradas fruto de una homonimia diacrónica, sobre fenómenos semántico-evolutivos de la lengua de origen de algunos términos, lo que excede los límites del repertorio y crea desajustes en su propia estructura interna.

4 Nada se dice acerca de la postura sobre la problemática homonimia en las "Advertencias para el uso de este diccionario", del DraE92. 
Incluir en un repertorio una marca de transición semántica como la que nos ocupa hace que haya que estar muy atentos a la evolución particular de cada lexema, de las familias de palabras de cada lexema y de los lexemas integrantes de su mismo campo léxico o de otros afines; y ello cuando no disponemos de información global sobre la evolución de los términos de nuestra lengua ${ }^{5}$. Por esta razón, tampoco es de extrañar que, sin un motivo aparente, existan acepciones en las que echamos en falta la indicación figurado. Veamos algunos ejemplos: en la entrada rayal, cuya primera acepción es 'línea o señal larga y estrecha que por combinación de un color con otro, por pliegue o por hendedura poco profunda, se hace o forma natural o artificialmente en un cuerpo cualquiera', la décima acepción 'en el lenguaje de la droga, dosis de cocaína' carece de la marca de uso figurado, cuando hay un evidente salto semántico por metonimia (la forma es lo que relaciona la primera y la décima acepciones); respecto de la entrada ratal, cuya primera acepción se refiere al animal mamífero roedor, nos encontramos con la séptima acepción, sin marca de transición semántica, redactada así: 'com. fam. Persona tacaña', y aquí sí que no puede hablarse de irradiaciones metafóricas, de simples extensiones significativas; lo que hay es un auténtico desplazamiento significativo con cambio de paradigma léxico. En la entrada rabo, cuya primera acepción remite a colal 'extremidad del cuerpo y de la columna de algunos animales', se incluye una séptima, marcada como vulgar, 'miembro viril', sin marca figurado. En el sustantivo raíz aparecen con la marca figurado la tercera acepción 'parte de cualquier cosa, de la cual, quedando oculta, procede lo que está manifiesto' y la cuarta 'parte inferior o pie de cualquier cosa', pero no la quinta 'causa u origen de algo'. En el adjetivo razonable la tercera acepción es figurada: 'mediano, regular, bastante en calidad o en canti-

5 Sí contamos con información parcial sobre campos léxicos -muchas tesis doctorales estudian la evolución de dominios significativos específicos- o sobre lexemas aislados, y en los diccionarios etrimológicos, sobre todo en el de Corominas y Pascual (1980-1991), podemos encontrar valiosos comentarios sobre la evolución semántica de muchos lexemas, pero, vuelvo a insistir en ello, carecemos, ya que el diccionario histórico auspiciado por la Academia continúa detenido en las primeras letras, de un diccionario del español como lengua histórica. 
dad', a partir de una primera acepción 'arreglado, justo, conforme a razón', pero en la entrada de su adverbio derivado, razonablemente, no hay ya marcada como figurada ninguna acepción, aunque su artículo es similar en su estructura lexicográfica y semántica: 'adv. m. Conforme a la razón' y 'más que medianamente'.

\section{EL SIGNIFICADO DE LA MARCA FIGURADO: SU INCLUSIÓN EN EL DICCIONARIO DE USO DE LA RAE}

Por lo que respecta a cuál es la acepción que da lugar a la transición semántica, indagar y elegir fundamentadamente la acepción prototípica en un repertorio usual que, además, quiere dar cuenta de las evoluciones semánticas del lexema definido y de su devenir cronológico, exige un esfuerzo titánico que, por la propia naturaleza de la empresa, no suele tener los resultados deseados. En primer lugar, el significado de una marca como ésta puede convertirse en un peligroso útil de trabajo dentro de un diccionario de uso, pues superpone un criterio evolutivo que, en ocasiones, lleva a colocar en primer lugar acepciones que no son las más usadas. Veamos, por ejemplo, la entrada recalcar, cuya primera acepción 'tr. Ajustar, apretar mucho una cosa con otra o sobre otra' es, indudablemente, prácticamente desconocida en la actualidad frente a la tercera figurada 'tratándose de palabras, decirlas con lentitud y exagerada fuerza de expresión para que no pueda quedar duda alguna acerca de lo que con ellas quiere darse a entender', mucho más usada que la primera; o el caso de recalar, con una primera acepción también poco usada en la sincronía presente 'tr. Penetrar poco a poco un líquido por los poros de un cuerpo seco, dejándolo húmedo o mojado ...', frente a la segunda acepción intransitiva y figurada 'aparecer por algún sitio una persona'; o la entrada del sustantivo ruina, cuya primera acepción 'acción de caerse o destruirse una cosa' es menos usada que los signifi-

6 Recordemos que más arriba nos hemos referido a rabiosamente frente a rabioso, sa; pues bien, en el caso de rabiosamente sí se marca con figurado la segunda acepción 'violenta, intensa o vehementemente', que es paralela a la cuarta acepción de rabioso, sa 'vehemente, excesivo, violento'. 
cados figurados que ha desarrollado como segunda acepción: 'pérdida grande de los bienes de fortuna', tercera: 'destrozo, perdición, decadencia y caimiento de una persona, familia, comunidad o Estado', y cuarta: 'Causa de esta caída, decadencia o perdición, así en lo físico como en lo moral'. Esta discrepancia entre uso y evolución ha sido puesta de manifiesto por $\mathrm{M}^{\mathrm{a}}$. Dolores Muñoz Núñez (1999: 188-189), en su reciente libro sobre la polisemia léxica, refiriéndose precisamente a la marca figurado en el DRAE92, señala que: "sin embargo, en algunos de estos casos estas acepciones son efectivamente poco o nada frecuentes, ya que pertenecen a determinados ámbitos específicos, y por tanto, no compartidas por todos los hablantes de una comunidad lingüística, lo cual va en contra del criterio académico según el cual los usos figurados ocupan un lugar determinado frente a las acepciones de uso corriente u otras".

Además de esta primera dificultad en la aplicación práctica de la marca estudiada, existe otra que deriva de la indefinición misma del término figurado como concepto metalexicográfico. Encontrar información teórica sobre lo que significa este término no es fácil. El DRAE92 dice en la tercera acepción de la entrada figurado como adjetivo: 'dícese del sentido en que se toman las palabras para que denoten idea diversa de la que recta y literalmente significan'. Volvemos pues al inicio de nuestro trabajo, como decía el profesor Seco es una marca de transición semántica, pero ¿cualquier transición semántica viene señalada con esta indicación? Desde luego que no. En la entrada rincón hay desplazamiento semántico en las acepciones segunda: 'escondrijo o lugar retirado' y tercera: 'espacio pequeño', frente a la primera: 'ángulo entrante que se forma en el encuentro de dos paredes o de dos superficies', y lo mismo sucede en ribete 'cinta o cosa análoga con que se guarnece y refuerza la orilla del vestido, calzado, etc.', con la segunda $\mathrm{y}$ tercera acepciones sin marcar como figuradas ('añadidura, aumento, acrecentamiento' y 'entre jugadores, interés que pacta el que presta a otro una cantidad de dinero...'), pero ya con la indicación figurado en la cuarta y la quinta ('adorno que en la conversación se añade en algún caso, refiriéndolo con alguna circunstancia de reflexión o de gracia' y 'asomo, indicio. Tiene sus RIBETES de poeta'). Parece que lo que de- 
termina la aparición de esta marca es la transición significativa que va, por las causas semánticas que sea, de lo concreto a lo abstracto; al menos, es lo que se deduce de muchos de los ejemplos extraídos de nuestro corpus. Así, en un caso como el del sustantivo amor 'sentimiento', no se marca como figurada la acepción quinta 'persona amada, invocada o llamada por quien la ama. AMOR mío.', a pesar de apartarse su contenido del significado literal primigenio; $\mathrm{y}$, sin embargo, en rezumar 'dicho de un cuerpo, dejar pasar a través de sus poros o intersticios gotitas de algún líquido', la tercera acepción traslaticia pero de significado abstracto sí lleva dicha marca: 'prnl. fig. y fam. Traslucirse y susurrarse una cosa'. Pero tampoco esta máxima se cumple en todos los casos; en ejemplos como raudal 'caudal de agua que corre violentamente', con una segunda acepción figurada 'abundancia de cosas que rápidamente y como de golpe concurren o se derraman'; rayano,na 'que confina o linda con una cosa', con la tercera acepción figurada 'cercano, con semejanza que se aproxima a igualdad' o radiante 'brillante, resplandeciente', con una segunda acepción figurada 'que siente o manifiesta gozo o alegría grandes', o también ramplón, na 'aplícase al calzado tosco y de suela muy gruesa y ancha', con segunda acepción figurada 'vulgar, chabacano', podría aceptarse este paso de lo concreto a lo abstracto, entendiendo lo abstracto en un sentido muy amplio; pero no se aplica así la marca estudiada en entradas como las de rabicorto, ta o rugido. La Academia define rabicorto, ta como 'dícese del animal que tiene corto el rabo' y añade una segunda acepción figurada 'aplícase a la persona que vistiendo faldas o ropas talares, las usa más cortas de lo regular', y de rugido dice el DRAE92 en su segunda acepción 'm. Voz del león', añadiendo otras tres figuradas: 'grito o dicho del hombre colérico y furioso', 'estruendo, retumbo' y 'ruido que hacen las tripas'.

En los dos últimos ejemplos es visible, por otro lado, la vieja polémica lexicográfica sobre la extensión y forma de los artículos de diccionario: o bien un artículo muy preciso que desmenuce los significados prototípicos en subacepciones, incluyendo invariantes y variantes significativas; o bien un artículo semánticamente globalizador, que se centre sólo en las invariantes. Pues bien, la marca figurado muchas veces introduce subacepciones, adaptando la terminología coseriana, 
"irradiaciones significativas", no invariantes de significado, que, en la mayoría de los casos constituyen extensiones lógicas de la actividad, cualidad u objeto a que se refiere el significado recto a otras actividades, cualidades u objetos en la acepción figurada, borrándose los límites con la marca por extensión (por ext.). Así sucede en ranciedad 'cualidad de rancio de los alimentos y del vino', con una segunda acepción figurada 'cualidad de rancio de las cosas antiguas y de las personas apegadas a ellas', o en ramalazo 'golpe dado con el ramal' con una segunda acepción general 'señal que deja el golpe dado por el ramal' y una tercera figurada, que extiende a otros tipos de señales el significado consignado en la acepción anterior: 'pinta o señal que sale al rostro u otra parte del cuerpo por un golpe o por enfermedad, como la erisipela'. Las acepciones figuradas de estas entradas son de naturaleza similar a otras que se marcan con la indicación por extensión en el DRAE92, como radicalismo 'calidad de radical', que desarrolla una segunda acepción 'conjunto de ideas y doctrinas de los que, en ciertos momentos de la vida social, pretenden reformar total o parcialmente el orden político, científico, moral y aun religioso' y una tercera 'por ext., el modo extremado de tratar los asuntos', o rampa2 'plano inclinado dispuesto para subir y bajar por él', con una segunda acepción 'por ext., terreno en pendiente'.

\section{LA MARCA FIGURADO EN OTROS DICCIONARIOS DE USO}

La indefinición de la marca figurado, de cuyos problemas hemos hecho un somero repaso tomando como referencia el DRAE92, ha suscitado diversas soluciones semánticas y lexicográficas. Ramón Trujillo (1996: 72-73) critica duramente su empleo en el DrAE92 pues, según él, la distinción entre los significados rectos y los figurados está fundamentada en criterios arbitrarios y no científicos; textualmente se expresa así: "A juzgar por lo que dice el Diccionario, parece que viene a ser lo mismo «acepción» que «sentido figurado», ya que, para empezar, unas y otras se cuentan siempre como acepciones, sin que sea posible

7 Coseriu (1986: 44) utiliza exactamente la denominación "irradiaciones metafóricas". 
saber objetiva y explícitamente cuándo significan de manera «recta» y cuándo no lo hacen. Se parte de una noción de «significado recto», según la cual unas acepciones son o parecen ser sentidos figurados y otras no, cuando, en realidad, ese supuesto significado recto no es más que una acepción cualquiera, elegida con algún criterio arbitrario (el que tenía en latín, el más antiguo que se documenta, etc.) y en absoluto semántico". Otros autores, como Mª . Dolores Muñoz Núñez (1999: 189), proponen un uso restringido de la marca figurado en los diccionarios, acudiendo al criterio de usualidad. Para Muñoz Núñez, la distancia semántica entre el significado recto y el uso figurado (y también otros sentidos de ámbitos específicos que recubren otras marcas diatópicas, diastráticas y diafásicas), y el que la acepción así marcada sea de, en sus propias palabras, "ámbito generalizado", decidiría la eliminación de la marca y aporta ejemplos como garganta 'desfiladero', con figurado en el DRAE92, corazón 'centro de una fruta', también con marca figurado en el diccionario académico o niño 'persona con poca experiencia' figurado también para la Academia. Estas dos posturas semánticas, la de Ramón Trujillo, radical en cuanto al empleo de esta marca, y la de $M^{a}$. Dolores Muñoz Núñez, partidaria de empleos selectivos, tienen su correlato lexicográfico. En la $1^{a}$ edición del Diccionario de uso del español de María Moliner (1966-1967) ${ }^{8}$ aparece entre la lista de abreviaturas que emplea el repertorio la correspondiente a la marca figurado (fig.), pero María Moliner la emplea cuando la acepción o subacepción - este diccionario incluye subacepciones- se han apartado notablemente del significado original. Así, se indica el uso figurado de ramo en su séptima acepción 'rama de una ciencia' o recalcar en su segunda acepción 'acentuar cada sílaba de una cosa que se dice o insistir en ella de cualquier manera para mostrar empeño en que no pase inadvertida y sea comprendida'; sin embargo, cuando las acepciones, aunque usadas traslaticiamente, son deducibles a partir de alguna acepción del artículo que las incluya, no se marcan como figuradas, lo que se da sobre todo

8 La profunda revisión de que ha sido objeto esta obra lexicográfica recientemente, hace que tengamos que referirnos a las dos ediciones de este repertorio en nuestro cotejo con los usos de la marca estudiada en el DRAE92. 
en variantes de significados que María Moliner señala como subacepciones. Por ejemplo, en el caso de ramalazo la primera acepción hace referencia al golpe que se da, la segunda subacepción, equivalente a la tercera acepción del repertorio académico, que considera todos los significados como acepciones, no lleva indicación de uso figurado: 'Señal semejante [a la que se produce al golpear con un ramal o rama] debida a otra cosa, por ejemplo erisipela', y sí lleva dicha marca en el DRAE92, y lo mismo sucede en otros casos en que la Academia marca una acepción con figurado y por la misma razón. De este modo aparecen sin esta indicación en María Moliner los significados 'se aplicaba a personas que llevaban demasiado cortas las vestiduras talares', de rabicorto, ta; 'hacer averiguaciones para encontrar a cierta persona', de rastrear o 'insuficiente, o en menos cantidad de la necesaria o conveniente', de raquítico, ca. Ahora bien, con el mismo criterio de acepción o subacepción deducible de otro significado pensamos que podría haberse eliminado la mención al uso figurado en entradas como radiante, con una segunda acepción figurada 'resplandeciente. Se aplica a la persona que muestra de manera impresionante o con exaltación algo como belleza, alegría o felicidad' o rebosar, con una segunda acepción también figurada, al igual que en la Academia: 'existir una cosa en extraordinaria abundancia'.

Tal vez han sido estos problemas en el empleo de una marca como la que venimos estudiando lo que ha decidido a prescindir por completo de ella a los revisores de la segunda edición del Diccionario de uso del español (1998), que ha visto recientemente la luz editorial. En los preliminares de la obra se informa de que las indicaciones que se ofrecen en el diccionario han sido objeto de una minuciosa revisión y, aunque no se señala explícitamente que se ha renunciado a la marca figurado, ni siquiera aparece en la tabla de abreviaturas empleadas por el repertorio.

Por último, en otro diccionario de reciente publicación, el Diccionario del español actual, de Manuel Seco, Olimpia Andrés y Gabino Ramos (1999), se hace un uso muy restringido de la marca figurado, favorecido por las características mismas del propio repertorio. Estamos ante una obra singular en el panorama de la lexicografía española, pues 
es un diccionario cuya planta es completamente nueva, diseñada por sus redactores y estrictamente ceñido a un corpus seleccionado para dar cuenta de los empleos actuales de los vocablos. Ello hace que las decisiones tomadas acerca de la estructura interna y externa del diccionario estén justificadas y aplicadas sin contradicción dentro del repertorio. El hecho de ceñirse a los usos actuales hace que carezca de sentido marcar significados como figurados, cuando no se va a dar cuenta de una hipotética evolución sobre significados anteriores usuales o no, y cuando muchas veces encabezan el artículo lexicográfico o un grupo de acepciones concreto. Por ello, la mayoría de los ejemplos que hemos extraído del DraE92, marcados como de uso figurado, no lo están en el Diccionario del español actual; esto sucede con rabieta 'enfado', raquítico, ca 'escaso', reanudar 'continuar una actividad', raspa 'persona irritable', rumiar 'reflexionar' y otros muchos ejemplos, pues son los significados actuales y dentro de este diccionario eso los hace indiferentes a su evolución anterior. Ahora bien, no se renuncia a señalar en esta obra el hecho de que un significado tenga un empleo traslaticio que no altere en lo básico el semema del término y no merezca por tanto una nueva acepción o subacepción; en ese caso, se indica esta información con la abreviatura "fig." (figurado), pero situada detrás de la definición, como en los lexemas radiantel', con una segunda acepción redactada así: 'muy brillante o luminoso. Tb. fig.' o rebosarA, cuya primera acepción dice 'derramarse [un líquido] por encima de los bordes del recipiente que lo contiene. Frec. fig.'. Los propios autores de la obra dan cuenta de esta forma de indicar los usos figurados de un término en la Guía del lector, que antecede al propio diccionario: "La existencia de un uso metafórico, cuando no está lo suficientemente independizado respecto al sentido definido y no parece definitivamente cuajado en otro distinto, se advierte por medio de la nota también figurado (tb. fig.)" (1999: xxii).

No se nos escapa que el empleo de marcas de cualquier tipo en un repertorio léxico implica una profunda reflexión previa sobre su contenido y la manera en que su empleo afectará a la estructura general del diccionario. Los artículos lexicográficos no son piezas aisladas, sino que deben encajar en el complejo rompecabezas que supone una obra 
de este tipo. En el caso de la marca estudiada es además determinante el tipo de repertorio en el que vaya a utilizarse, y no sólo el significado con que se dota a la marca misma. Por eso probablemente hemos visto diversas soluciones en su empleo, dependiendo de que el diccionario sea exclusivamente sincrónico o no. Tal vez lo más acertado lexicográficamente sería reservar una información así a repertorios históricos, en que es obligado pronunciarse sobre la historia semántica de los términos. Por ello en los repertorios totalizadores, híbridos entre una visión vertical y otra horizontal de la lengua, sobre todo en el repertorio académico, el empleo de una marca como esta ha planteado innumerables problemas.

\section{BIBLIOGRAFÍA}

ACAdEMIA, Real ........ EsPañola (1992): Diccionario de la lengua española, Madrid, Espasa-Calpe, vigésima primera ed.

COROMINAS, Joan (1980-1991): Diccionario crítico etimológico castellano e hispánico, con la colaboración de José A. Pascual, Madrid, Gredos, 6 vols.

COSERIU, Eugenio (1986): "Para una semántica diacrónica estructural”, en Principios de semántica estructural, Madrid, Gredos, $2^{\mathrm{a}}$ ed., pp. 786.

Moliner, María (1966-1967): Diccionario de uso del español, Madrid, Gredos, $1^{\text {a }}$ ed., 2 vols.

— (1998): Diccionario de uso del español, Madrid, Gredos, $2^{\text {a }}$ ed., 2 vols.

MuÑoz NÚÑEZ, Må . Dolores (1999): La polisemia léxica, Cádiz, Universidad de Cádiz.

SeCo, Manuel (1987): "Problemas formales de la definición", en Estudios de lexicografía española, Madrid, Paraninfo, pp. 15-34.

SeCo, Manuel, Olimpia AndRÉs y Gabino RAmos (1999): Diccionario del español actual, Madrid, Aguilar, 2 vols.

Trujillo, Ramón (1996): Principios de semántica textual, Madrid, Arco/Libros. 